Research Perspective

\title{
Menin: Expanding and dichotomous roles in cancer
}

\author{
Bryson W. Katona ${ }^{1,2}$, Rebecca A. Glynn², Taylor A. Hojnacki ${ }^{2}$ and Xianxin Hua ${ }^{2}$ \\ ${ }^{1}$ Division of Gastroenterology, University of Pennsylvania Perelman School of Medicine, Philadelphia, Pennsylvania \\ ${ }^{2}$ Department of Cancer Biology, Abramson Family Cancer Research Institute, University of Pennsylvania Perelman School of \\ Medicine, Philadelphia, Pennsylvania
}

Correspondence to: Bryson W. Katona email: bryson.katona@pennmedicine.upenn.edu

Xianxin Hua

huax@pennmedicine.upenn.edu

Keywords: menin; colorectal cancer; SKP2; EGFR inhibitor

Received: June 12, $2019 \quad$ Accepted: June 14, 2019

Published: August 23, 2019

Copyright: Katona et al. This is an open-access article distributed under the terms of the Creative Commons Attribution License 3.0 (CC BY 3.0), which permits unrestricted use, distribution, and reproduction in any medium, provided the original author and source are credited.

Menin, the protein product of the MEN1 gene, is a ubiquitously expressed protein that lacks homology with other protein families, yet is highly conserved among various species [1]. Menin primarily resides in the nucleus, where it serves as a scaffold for epigenetic regulators $[1,2]$. While much is known about menin and its diverse roles in numerous cellular processes, there remains much to be discovered, especially with regard to its role in cancer.

\section{Menin and cancer}

The first association of menin with cancer was recognized through the study of multiple endocrine neoplasia type 1 (MEN1) syndrome [1]. Individuals with the autosomal dominant MEN1 syndrome have a germline mutation in the MEN1 gene that leads to increased risk of pituitary, parathyroid, and pancreatic neuroendocrine tumors. For these particular tumors menin clearly serves as a tumor suppressor, however this tumor suppressor function is not global amongst all types of cancers. In fact, menin serves as a contextual tumor promoter in MLL-fusion leukemia. Menin promotes MLL- and MLLfusion protein-induced increases in $\mathrm{H} 3 \mathrm{~K} 4$-trimethylation and HOX gene expression, which is critical for leukemogenesis [3]. Consequently, inhibitors of menin (MIs) are effective in the treatment of this subset of leukemias in preclinical models [3]. Additionally, menin serves as a contextual tumor promoter in prostate cancer, where menin/MLL acts as an important co-activator of the androgen receptor [4]. Consistently, MIs also demonstrate anti-neoplastic effects in prostate cancer [4].

Our group recently showed that menin is overexpressed in colorectal cancer (CRC) compared to normal colonic mucosa [5]. CRC cell growth does not depend on functional menin, unlike MLL-fusion leukemias and prostate cancer. However, we found menin is important for CRC resistance to small molecule EGFR inhibitors (iEGFR) such that combined treatment of CRC with a MI and iEGFR led to synergistic cell death through transcriptional suppression of the E3 ubiquitin ligase SKP2 (Figure 1). There are several important points to highlight from these recent findings. First, this synergy is independent of EGFR, and is instead dependent on iEGFR-induced increases in cytosolic calcium. We found that iEGFRs induce activation of inositol trisphosphate receptor 3 (IP3R3), causing release of ER calcium to the cytoplasm. Second, menin is critical for maintaining expression of pro-tumorigenic SKP2, which is necessary for ubiquitin-mediated degradation of anti-proliferative proteins, such as $\mathrm{p} 27$. Menin binds the $S K P 2$ promoter and facilitates MLL-mediated H3K4-trimethylation to maintain SKP2 expression. Third, menin directly binds calcium, and increased cytosolic calcium reduces menin's ability to promote transcription of SKP2. Taken together, these results reveal a novel role for menin in regulating $\mathrm{CRC}$ and a new mechanism to potentially develop novel therapeutic combinations for CRC.

\section{Challenges and future directions}

While menin is increasingly recognized as being important in regulating cancer, whether menin suppresses or promotes growth appears to be highly tissue specific. The role of menin in other cancers apart from CRC, prostate, MLL-fusion leukemias, and MEN1 syndrome spectrum tumors is largely unknown and certainly merits further investigation. Furthermore, there is a clear need to better understand the in-depth biology of menin. In our recent work, we reveal a novel cross-talk between menin and EGFR inhibitor-induced calcium release that converges on regulation of SKP2 transcription [5]. There are undoubtedly numerous other menin-related signaling pathways that remain to be discovered, and these pathways 
will likely be integral in maintaining the epigenomes of various types of cancers, as well as the epigenomes in various cognate normal tissues. Additionally, how calcium may alter the function of menin and menin-mediated epigenetic regulation should be further investigated.

Given the increasing number of cancers where menin serves pro-tumor roles, developing effective menin inhibitors is of the utmost importance. Small molecule MIs have been developed by several groups [3, 6], and some of these MIs are orally bioavailable and display efficacy in mouse models [3]. Recent work on a menin/ MLL inhibitor KO-539 by Kura Oncology has led to the first FDA approval of an investigational new drug (IND) application for a small molecule MI [7]. This approval will likely lead to an initial phase I study in humans, which is an important first step in working to translate MIs from the bench to the bedside.

Our work linking menin to CRC highlights the importance of investigating the use of MIs with other antineoplastic agents. iEGFRs alone have not demonstrated clinical success in treating CRC $[8,9]$, however, if a MI can be developed to the clinical market, it is important to readdress whether patients with metastatic CRC may benefit from combination therapy with an iEGFR and MI. Furthermore, there may be benefit with combining MIs with iEGFRs in other cancers where iEGFRs are currently clinically approved and utilized in treatment, such as in non-small cell lung cancer with activating EGFR mutations [10]. Additionally, as MIs synergized with the EGFR-independent effects of iEGFRs [5], it is important to remember that many approved drugs have "off-target" effects, and that exploiting these "off-target" effects can potentially be a successful strategy to increase their efficacy.

\section{Conclusion}

While recent exciting work focused on better understanding the role of menin in cancer, much remains to be discovered. Important priorities necessary to advance the field forward include understanding the unique role of menin in other cancers, elucidating the complex cellular and biochemical functions of menin, and developing effective menin inhibitors that can be translated to clinical trials.

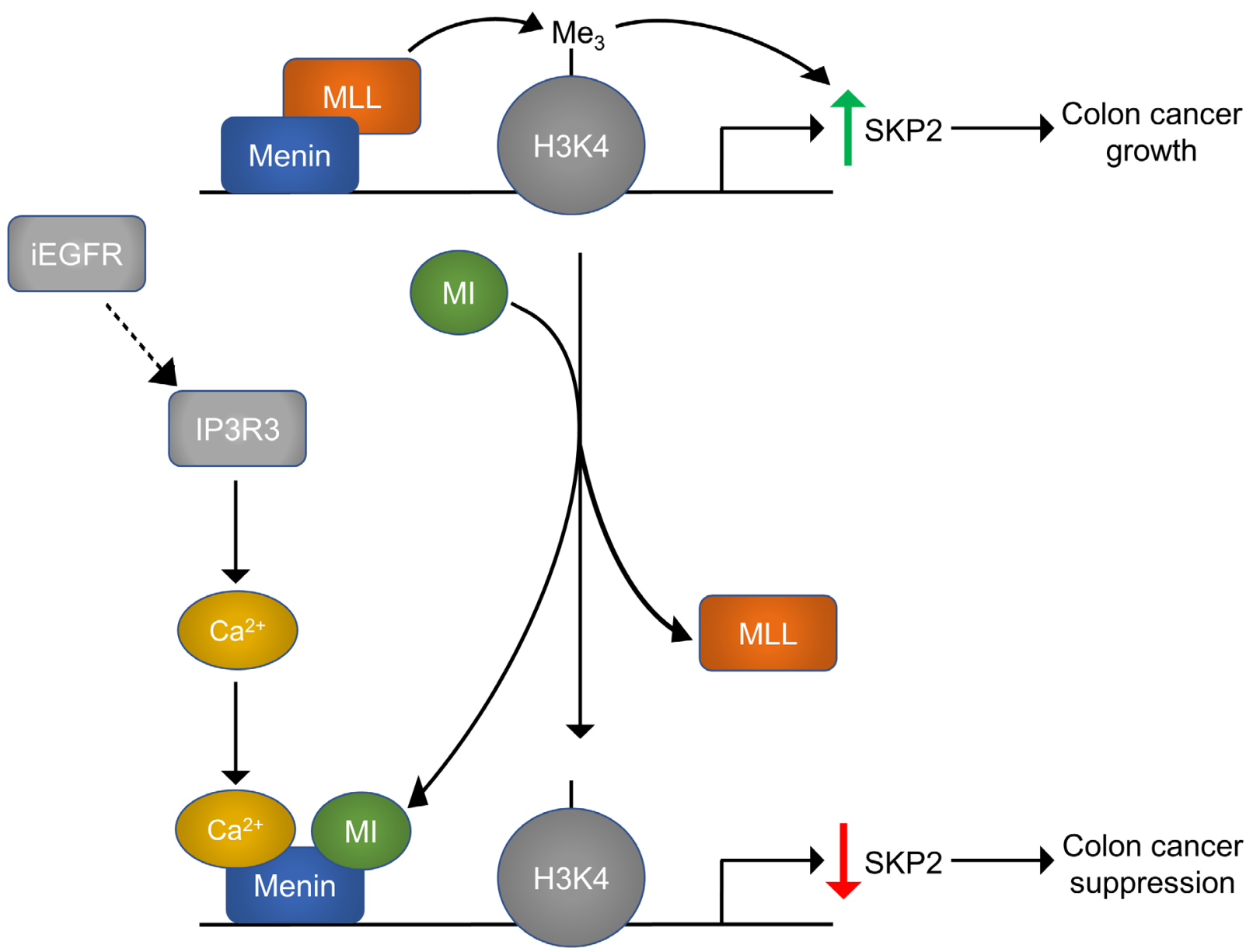

Figure 1: The combination of a menin inhibitor (MI) and small molecule EGFR inhibitor (iEGFR) synergistically suppress CRC through repression of SKP2 transcription. 


\section{CONFLICTS OF INTEREST}

The authors declare no potential conflicts of interest.

\section{FUNDING}

Support was provided by NIH/NIDDK K08DK106489 (BWK), NIH/NIDDK R01DK097555 $(\mathrm{XH})$, and NIH/NCI R01CA178856 (XH), the NIH/ NIDDK Center for Molecular Studies in Digestive and Liver Diseases at the University of Pennsylvania (P30DK050306, BWK), the Institute for Translational Medicine and Therapeutics at the University of Pennsylvania $(\mathrm{XH})$, and the Lustgarten Family Colon Cancer Research Fund (BWK).

\section{REFERENCES}

1. Li JW, Hua X, Reidy-Lagunes D, Untch BR. MENIN loss as a tissue-specific driver of tumorigenesis. Mol Cell Endocrinol. 2018; 469:98-106. https://doi.org/10.1016/j. mce.2017.09.032. [PMID:28965973]

2. Matkar S, Katona BW, Hua X. Harnessing the hidden antitumor power of the MLL-AF4 oncogene to fight leukemia. Cancer Cell. 2014; 25:411-13. https://doi. org/10.1016/j.ccr.2014.03.028. [PMID:24735921]

3. Borkin D, He S, Miao H, Kempinska K, Pollock J, Chase J, Purohit T, Malik B, Zhao T, Wang J, Wen B, Zong H, Jones M, et al. Pharmacologic inhibition of the Menin-MLL interaction blocks progression of MLL leukemia in vivo. Cancer Cell. 2015; 27:589-602. https://doi.org/10.1016/j. ccell.2015.02.016. [PMID:25817203]

4. Malik R, Khan AP, Asangani IA, Cieślik M, Prensner JR, Wang X, Iyer MK, Jiang X, Borkin D, Escara-Wilke J, Stender R, Wu YM, Niknafs YS, et al. Targeting the MLL complex in castration-resistant prostate cancer. Nat Med. 2015; 21:344-52. https://doi.org/10.1038/nm.3830. [PMID:25822367]

5. Katona BW, Glynn RA, Paulosky KE, Feng Z, Davis CI, Ma J, Berry CT, Szigety KM, Matkar S, Liu Y, Wang H, Wu Y, He X, et al. Combined Menin and EGFR Inhibitors Synergize to Suppress Colorectal Cancer via EGFRIndependent and Calcium-Mediated Repression of SKP2 Transcription. Cancer Res. 2019; 79:2195-207. https://doi. org/10.1158/0008-5472.CAN-18-2133. [PMID:30877106]

6. Shi A, Murai MJ, He S, Lund G, Hartley T, Purohit T, Reddy G, Chruszcz M, Grembecka J, Cierpicki T. Structural insights into inhibition of the bivalent meninMLL interaction by small molecules in leukemia. Blood. 2012; 120:4461-69. https://doi.org/10.1182/ blood-2012-05-429274. [PMID:22936661]

7. Burrows F, Wu T, Kessler L, Li S, Zhang J, Zarrinkar P, Li L, Cierpicki T, Grembecka J, Ren P, Liu Y. Abstract LB-A27: A novel small molecule menin-MLL inhibitor for potential treatment of MLL-rearranged leukemias and NPM1/DNMT3A-mutant AML. Mol Cancer Ther. 2018; 17. https://doi.org/10.1158/1535-7163.TARG-17-LB-A27

8. Mackenzie MJ, Hirte HW, Glenwood G, Jean M, Goel R, Major PP, Miller WH Jr, Panasci L, Lorimer IA, Batist G, Matthews S, Douglas L, Seymour L. A phase II trial of ZD1839 (Iressa) $750 \mathrm{mg}$ per day, an oral epidermal growth factor receptor-tyrosine kinase inhibitor, in patients with metastatic colorectal cancer. Invest New Drugs. 2005; 23:165-70. https://doi.org/10.1007/s10637-005-5862-9. [PMID: 15744593]

9. Townsley CA, Major P, Siu LL, Dancey J, Chen E, Pond GR, Nicklee T, Ho J, Hedley D, Tsao M, Moore MJ, Oza AM. Phase II study of erlotinib (OSI-774) in patients with metastatic colorectal cancer. Br J Cancer. 2006; 94:1136-43. https://doi.org/10.1038/sj.bjc.6603055. [PMID:16570047]

10. Maemondo M, Inoue A, Kobayashi K, Sugawara S, Oizumi S, Isobe H, Gemma A, Harada M, Yoshizawa H, Kinoshita I, Fujita Y, Okinaga S, Hirano H, et al, and North-East Japan Study Group. Gefitinib or chemotherapy for non-small-cell lung cancer with mutated EGFR. N Engl J Med. 2010; 362:2380-88. https://doi.org/10.1056/NEJMoa0909530. [PMID:20573926] 